\title{
PENSAMENTO CRÍTICO DE ANTONIO CANDIDO: ALGUMAS CONSIDERAÇÕES
}

\section{THE ANTONIO CANDIDO'S CRITICAL THOUGHT: SOME CONSIDERATIONS}

\author{
Ana Paula Lima Carneiro ${ }^{1}$ \\ Manoel Freire Rodrigues ${ }^{2}$ \\ Universidade do Estado do Rio Grande do Norte - UERN
}

\section{RESUMO}

O presente artigo teve por objetivo apresentar algumas considerações acerca do pensamento crítico de Antonio Candido, refletindo sobre a importância de suas ideias para crítica literária brasileira. Analisar-se-á a relação que o referido crítico brasileiro estabelece entre a arte literária e a vida social, ou seja, a relação dialógica entre ambas. Para tanto, o artigo foi realizado por meio de pesquisa bibliográfica, através da utilização de textos de Antonio Candido, como também ensaios de outros estudiosos acerca do referido crítico, tais como Schwarz (1987) e (1999), Lajolo (2003), Crespo (2003), Barbosa (2007), dentre outros. A partir da realização da pesquisa podemos inferir que o pensamento crítico de Antonio Candido é muito importante para a crítica brasileira, e que, por meio da leitura de algumas de suas produções, podemos observar um jogo de diálogos existente entre a obra literária e a vida social.

PALAVRAS-CHAVE: Antonio Candido. Pensamento crítico. Diálogo.

\begin{abstract}
This article objected to expose some considerations about the Antonio Candido's critical thought, reflecting about the importance of his ideas to the Brazilian literature critics and to analyze, in some of his texts, the dialogical relation that the mentioned critic establishes between the literary art and the social life. For this, the article was realized through bibliographic research based on conceptions of Schwarz (1987) and (1999), Lajolo (2003), Crespo (2003), Barbosa (2007), among other. Through realization of research, we can deduce that Antonio Candido's critical thought is one of the most important legacy to Brazilian literature critics, as well as, through reading some of his productions, we can observe a dialogical game between the literary work and the social life, perceiving, through his vision of literary historian, the literature as aculture integrated system.
\end{abstract}

KEYWORDS: Antonio Candido. Critical thought. Dialogue.

\footnotetext{
1 Mestranda em Letras pela Universidade do Estado do Rio Grande do Norte - UERN, E-mail: anapaulalimaf2@hotmail.com

${ }^{2}$ Doutor em Teoria e História Literária pela Universidade Estadual de Campina, professor de literatura brasileira da Universidade do Estado do Rio Grande do Norte - UERN, docente permanente do Programa de Pós-graduação em Letras da mesma Universidade, E-mail: manoelfrr@gmail.com
} 


\section{INTRODUÇÃO}

O presente estudo teve como objetivo apresentar algumas considerações acerca do pensamento crítico de Antonio Candido, destacando a sua importância para o cenário crítico brasileiro, e discutir acerca da dialética existente em suas obras, considerando a obra literária como um sistema integrado de cultura, ou seja, observando o intercâmbio entre a obra literária e a sociedade, a relação entre a arte literária e a vida social.

Para tanto, o artigo encontra-se estruturado em dois tópicos. No primeiro tópico, intitulado "Contribuições de Antonio Candido para a crítica literária brasileira", abordamos um pouco acerca do trabalho de um crítico, e apresentamos as contribuições de Roberto Schwarz (1987 e 1999), Marisa Lajolo (2003), Regina Crespo (2003), João Alexandre Barbosa (2007), e Sebastião Marques Cardoso (2013) acerca da obra de Antonio Candido, destacando a importância do seu pensamento para a crítica literária nacional.

No segundo tópico, intitulado "O jogo dialético de Antonio Candido", apresentamos algumas considerações acerca de algumas obras do crítico literário Antonio Candido, tais como Literatura e sociedade, e Formaşão da literatura brasileira, além dos ensaios "De cortiço a Cortiço" e "Dialética da malandragem". Nesta parte do estudo discutimos o jogo dialético entre a obra literária e a vida social, destacando como a literatura pode ser considerada um sistema integrado de cultura.

\section{Contribuições de Antonio Candido para a crítica literária brasileira}

O trabalho de um crítico literário é de suma importância para qualquer tipo de criação literária, porque contribui para que haja muitos debates acerca dos critérios para que uma obra literária seja considerada de qualidade. João Alexandre Barbosa, "[...] acredita ser a crítica um gênero literário", e que o limite entre crítica e criação literária é essencial para quem tem a responsabilidade de crítico, por ser uma atividade que está ligada à "[...] operação transformadora da linguagem" (BARBOSA, 2007, p. 45), ou seja, pensar crítica literária é pensar a criação literária. Com isso, é importante que o crítico literário seja alguém que escreve e que através das suas análises marque a sua presença, conforme podemos observar por meio das palavras de Barbosa (2007, p. 45): “A análise e juízo de valor são termos de uma atividade que se torna legítima na medida em que a sua expressão corresponde a um acréscimo de visão daquilo que se analisa ou se julga", fazendo com que o leitor tenha uma reflexão mais íntima de determinada produção. É por isso que "[...] a verdadeira crítica, isto é, aquela que continua a operar através de numerosos juízos sobre uma dada obra, possui sempre o seu conteúdo, por assim dizer, memorialístico" (BARBOSA, 2007, p. 46). É necessário que esse trabalho crítico dure, e que seja inovador, na medida em que apresenta uma reflexão acerca de pontos que ainda não foram percebidos.

No cenário da crítica nacional, um nome que merece destaque é do crítico literário Antonio Candido. De acordo com Roberto Schwarz (1999), Antonio Candido, em sua obra Formação da literatura brasileira faz um estudo histórico de uma formação que já havia se completado, considerando que na segunda metade do século XIX com Machado de Assis temos um sistema literário amadurecido. Conforme as palavras de Lajolo (2003), para o referido crítico literário só existe literatura porque existe sistema literário, tema discutido na referida obra, abordando a fundação, o desenvolvimento e a consolidação do sistema literário brasileiro.

A referida obra foi publicada em 1959, num período rico "[...] para os estudos literários dentro e fora do Brasil” (LAJOLO, 2003, p. 51). Schwarz (1999) ainda destaca que Antonio 
Candido ao abordar o desejo dos brasileiros de ter uma literatura nacional, destaca que ela só seria conseguida por meio de um processo de desprovincianização, deixando de ser subordinada a literatura europeia, ao buscar esse distanciamento, para tanto, o referido crítico começou a estudar a história dos brasileiros. Conforme as palavras de Schwarz, esse distanciamento não cancela os seus vínculos, ou seja, "Estamos longe das ilusões redentoras de nacionalismo, que o próprio Antonio Candido assinalaria no estudo sobre 'Literatura e subdesenvolvimento", (SCHWARZ, 1999, p.19).

É importante ressaltar, conforme as palavras de Schwarz (1999), que alguns criticam a Formação da literatura brasileira de Antonio Candido, por não incluir Gregório de Matos e padre Vieira, excluído dessa forma o barroco. Schwarz afirma que "[...] Antonio Candido tem um conceito materialista e não tradicionalista da tradição" (SCHWARZ, 1999, p. 20), já que para Antonio Candido a formação da literatura brasileira inicia-se no período em que o nacionalismo começou a se consolidar, no Arcadismo.

É importante ressaltar que não temos como não apresentarmos uma literatura influenciada pela tradição, conforme Schwarz (1999), não temos como lidar apenas com nosso país e região, porque vivemos em um mundo interligado em que retomamos a tradição mundial e inventamos tradições, já que o tempo das formações nacionais passou. Aspecto que é importante para o entendimento da formação da literatura brasileira, pois conforme é destacado por Lajolo (2003), o crítico literário Antonio Candido, no prefácio da segunda edição da obra Formação da literatura brasileira, argumenta que a literatura depende de certa continuidade da tradição, se configurando ao longo da história literária.

No tocante às concepções de Marisa Lajolo (2003) acerca do livro Formação da literatura brasileira, ela destaca que logo no início da produção de Antonio Candido, o referido autor apresenta a noção de sistema literário, e é sobre essa noção que ele constrói a sua crítica, fazendo a sua interpretação histórica e crítica da literatura brasileira.

Dessa forma, a literatura para a teoria de sistema literário desenvolvida por Antonio Candido, não pode ser considerada como um conjunto de textos com determinadas características, pois o conceito acerca do que é um texto literário deixa de ser identificado apenas pelos aspectos internos do texto, mas de acordo com a legitimação que recebe dentro do sistema literário, ou seja, dentro do contexto autor-leitor-público, ao qual circula. O conceito de sistema foi interpretado como núcleo, pois é a partir dele que os leitores se posicionam em relação à obra literária (LAJOLO, 2003), permitindo a configuração de uma literatura nacional, cujo embrião no Brasil é o Arcadismo.

Lajolo (2003) destaca que devemos levar em consideração a tradição dos estudos literários, mostrando a importância da leitura para o processo de formação da literatura brasileira. E, por meio da obra Formação da literatura brasileira, podemos observar essa importância, "[...] já que ela concebe a literatura como integração de autores, obras e público em um sistema articulado e não mais como pluralidade aleatória [...]" (LAJOLO, 2003, p. 56). Dessa forma, é possível relacionar a noção de sistema literário, apresentado por Antonio Candido, a alguns elementos dos estudos literários contemporâneos, dentre eles a intertextualidade, sendo que esse diálogo só acontece entre autor e público através da obra literária (LAJOLO, 2003), ou seja, o diálogo só é possível se existir um sistema literário, pois de acordo com Bakhtin (1988, p. 151) "O diálogo das linguagens não é somente diálogo das forças sociais na estática de suas coexistências, mas é também o diálogo dos tempos, das épocas, dos dias, daquilo que morre, vive, nasce; [...]", dessa forma, os textos estão em constante diálogo com a tradição, sofrendo influência tanto de fatores sociais como de outros textos. É importante destacar que essa teoria da literatura é formulada a partir da reflexão que o referido crítico faz acerca do caráter particular dos brasileiros. De acordo com Schwarz: 
[...] a constituição de um romance dá-se a partir de estímulos diretos da realidade? Não seria mais exato vê-la através da transformação de outros romances anteriores? Em lugar da alternativa, que é um falso problema, Antonio Candido dirá que os dois processos coexistem, e que a sua combinação é regulada, caso a caso, por uma fórmula singular, a qual é a chave da individualidade e da historicidade da obra. (SCHWARZ, 1999, p. 25)

Nesse sentido, Antonio Candido em sua crítica apresenta um sistema de relações sociais, ligando a obra ao meio social, e ao tempo. Sendo considerado, de acordo com Schwarz (1999), um dos críticos brasileiros que se beneficiou com uma formação atualizada em ciências humanas, e por seus escritos não se esgotarem, em outras palavras, o seu pensamento crítico continua nos debates teóricos atuais.

É importante ressaltar que a relação entre autor e público vai se modificando com o passar do tempo, dessa forma o "[...] desenvolvimento mais detalhado da noção de sistema literário pode constituir um passo decisivo para tornar os estudos literários mais rigorosos" (LAJOLO, 2003, p. 64), mostrando assim que a teoria desenvolvida por Antonio Candido é muito importante para os estudos literários nacionais. O referido crítico afirma em um estudo sobre $O$ cortiço que "[...] tanto é possível passar da observação literária à observação social como o contrário, e que a sua comunicação se destinava a exemplificar o segundo caminho" (SCHWARZ, 1999, p. 35), confirmando a estreita relação entre literatura e sociedade, ou seja, ente a obra literária e a realidade social.

Conforme as palavras de Crespo (2003), Antonio Candido, em seus escritos, manifestou uma preocupação com as relações entre o Brasil e o universo social e cultural hispano-americano, mostrando o compromisso que ele tem em fazer com que o Brasil alcance maior visibilidade entre os países americanos colonizados pela Espanha.

De acordo com Barbosa, Antonio Candido é “[...] o melhor crítico e historiador literário do Brasil, e possivelmente da América Latina, no século XX” (BARBOSA, 2007, p. 177), pois apresentou um caminho de referências importantes para os intercâmbios intelectuais, conforme ressalta Crespo:

É importante observar que, no terreno dos contatos entre brasileiros e hispanoamericanos - onde o elogio retórico costuma suplantar a ação concreta -, Candido logrou desenhar um mapa de referências importantes para os que nos preocupamos em refazer o caminho dos intercâmbios intelectuais e registrar sua história. (CRESPO, 2003, p. 98)

Conforme Crespo (2003), nos ensaios de Antonio Candido observa-se um enfoque histórico e sociológico, correntes teóricas que constroem nos brasileiros um pensamento social. A trajetória de Antonio Candido é composta por uma preocupação em cumprir o papel social de intelectual. $\mathrm{O}$ referido crítico estudou temas ligados à literatura e à sociedade, tais como cultura, 
história e política, criticando o conservadorismo político no Brasil e o egoísmo da elite do país por meio de um pensamento revolucionário.

Em "Dialética da malandragem", Antonio Candido reflete acerca da forma das memórias, entendendo que os personagens circulam no que ele define de esferas da ordem e da desordem social, e essa dialética organiza tanto os dados da ficção como os dados sociais, ou seja, mostrando a relação entre ficção e realidade. De acordo com Schwarz (1987, p. 140), “[...] trata-se de ler o romance sobre fundo real e de estudar a realidade sobre fundo de romance, no plano das formas mais que dos conteúdos, e isto criticamente". O que interessa Antonio Candido em "Dialética da malandragem" é:

\footnotetext{
Formalização estética de circunstâncias sociais; redução estrutural do dado externo; função da realidade histórica na constituição da estrutura de uma obra: de diferentes ângulos, são formulações do que interessa Antonio Candido neste ensaio. Designam o momento em que uma forma real, isto é, posta pela vida prática, é transformada em forma literária, isto é, em princípio de construção de um mundo imaginário. (SCHWARZ, 1987, p. 142)
}

A dinâmica estética se vincula ao social, ou seja, existe uma relação entre o romance e a vida real, sendo que a originalidade do ensaio de Antonio Candido não está no desejo de ligar literatura e sociedade, mas no modo firme com que ele "[...] se deixa guiar pelo discernimento formal, seja para discriminar as componentes de fatura do livro e estabelecer a sua organização, seja para buscar o seu correlato social, que será construído para explicar a forma" (Schwarz, 1987, p. 144).

É importante ressaltar que predominou no Brasil por muito tempo a crítica louvaminheira, sendo que, com a publicação da Formação da literatura brasileira de Antonio Candido, consolidou-se no Brasil uma crítica que, de acordo com as considerações de Cardoso (2013), converge tanto com nosso passado crítico, como com a produção crítica posterior, ou seja, dialoga com a crítica anterior, como por exemplo, a de José Veríssimo e Silvio Romero, e a posterior, os contemporâneos Roberto Schwarz e Luiz Costa Lima. Dessa forma, mostra a importância que a crítica de Antonio Candido exerce sobre a crítica literária nacional posterior, influenciando principalmente Roberto Schwarz.

\section{O diálogo em Antonio Candido: algumas considerações acerca de suas obras}

Em a Formação da literatura brasileira Antonio Candido faz um estudo acerca da literatura brasileira elaborando uma síntese de "[...] tendências universalistas e particularistas" (CANDIDO, 2000, p. 23). Esse foi o primeiro passo para uma nova forma de analisar a nossa literatura, fazendo uma interpretação da sociedade brasileira, estudando as obras literárias como um sistema, ou seja, como um conjunto interligado para entender determinado período, percebendo a formação da continuidade literária, elaborando dessa forma um conceito de sistema literário.

Desse modo, podemos observar que por meio de seu olhar histórico, Antonio Candido formulou uma crítica que leva em consideração os acontecimentos literários, revendo em uma perspectiva atual a velha concepção de crítica, estudando a literatura "[...] como expressão da realidade local e, ao mesmo tempo, elemento positivo na construção nacional" (CANDIDO, 2000 , p. 25). Compara as produções brasileiras com as de outras nacionalidades, indicando que a 
nossa literatura não sofre influência apenas europeia, mas dos aspectos sociais e culturais do Brasil, ou seja, considera que a literatura nacional é um ramo da portuguesa, mas que se tornou independente, ao reforçar nas obras literárias temas ligados à nacionalidade brasileira.

De acordo com Candido (2000, p. 29), “[...] o ponto de vista histórico é um dos modos legítimos de estudar literatura, pressupondo que as obras se articulam no tempo [...]" discernindo "[...] uma certa determinação na maneira por que são produzidas e incorporadas ao patrimônio de uma civilização", ou seja, um dos modos de estudar uma obra literária é levar em consideração o contexto social, observando como elas são ligadas a sociedade da época em que foi produzida e publicada.

Em Formação da literatura brasileira Antonio Candido também apresenta qual o papel do crítico literário, que é um trabalho analítico e interpretativo, pois de acordo com Candido (2000) o crítico é formado pelo desejo de compreender, para interpretar e explicar determinada produção artística. Não existe apenas um caminho para fazer crítica, mas vários, pois isso vai depender do objeto, considerado os fatores externos e internos à obra, pois nos dizer de Candido (2000) os elementos de compreensão são os fatores externos, que vinculam no tempo, e o fator individual, o autor, que produz e está presente no texto, lembrando que ele não se limita a estes aspectos, sendo considerado importante pela maneira como exprime os aspectos reais, pois o texto é formado pelo diálogo entre os elementos sociais e psíquicos.

Nesse sentido, podemos dizer que o crítico Antonio Candido apresenta uma nova perspectiva para a realização da análise crítica, ao pensar a questão do diálogo entre a obra literária e o contexto social. Observamos isso com maior notoriedade em seu ensaio "Crítica e sociologia", do livro Literatura e sociedade. Neste ensaio, o referido crítico formula vários tipos de correspondência entre literatura e sociedade, mostrando os aspectos sociais presentes nas produções literárias, mas sem uma interpretação efetiva.

Antonio Candido em seus textos "Crítica e sociologia" e "Literatura e a vida social" do livro Literatura e sociedade, por meio de um viés dialético apresenta a relação entre o interno, o "texto", e o externo, a "sociedade", mostrando que as obras literárias devem ser estudadas por meio de uma interpretação dialética entre ambos, sendo considerado o social um elemento que desempenha certo papel na constituição interna da obra, conforme podemos observar no seguinte trecho:

\begin{abstract}
Hoje sabemos que a integridade da obra não permite adotar nenhuma dessas visões dissociadas; e que só a podemos entender fundindo texto e contexto numa interpretação dialeticamente íntegra, em que tanto o velho ponto de vista que explicava pelos fatores externos, quanto o outro, norteado pela convicção de que a estrutura é virtualmente independente, se combinam como momentos necessários do processo interpretativo. Sabemos, ainda, que o externo (no caso, o social) importa, não como causa, nem como significado, mas como elemento que desempenha um certo papel na constituição da estrutura, tornando-se, portanto, interno. (CANDIDO, 2010, p. 13-14)
\end{abstract}

Dessa forma, para entender uma obra literária é necessário fundir texto e contexto, levando em consideração o diálogo entre ambos, pois o social é um elemento que desempenha um papel importante na construção do texto. No entanto, quando vamos fazer uma crítica literária, somos direcionados a analisar a organização interna das obras, que não deixa de ser externa, pois nessa organização o meio social também está presente, pelo motivo de o autor, 
durante a criação de uma obra literária, levar em consideração e/ou ser influenciado pelos aspectos sociais.

\begin{abstract}
Quando fazemos uma análise deste tipo, podemos dizer que levamos em conta o elemento social, não exteriormente, como referência que permite identificar, na matéria do livro, a expressão de uma certa época ou de uma sociedade determinada; nem como enquadramento, que permite situá-lo historicamente; mas como fator da própria construção artística, estudado no nível explicativo e não ilustrativo. (CANDIDO, 2010, p. 16-17).
\end{abstract}

Para tanto, o social deve ser visto como um aspecto que faz parte da estrutura do livro, ou seja, considerando o social como um fator que influencia a arte, dessa forma, o exterior tornase interno ao fazer parte da economia do livro. É importante ressaltar que Candido é contra a ideia de que tudo é explicado através do social, ou seja, que não devemos levar apenas em consideração os elementos sociais para analisar uma obra literária, pois devemos levar em consideração a relação entre a estrutura da obra (contexto interno e estético) e o processo social (contexto externo, histórico, de onde a obra provém), observando a absorção que ela carrega na configuração estética dos aspectos exteriores, da realidade do processo social.

No ensaio "A literatura e a vida social", Antonio Candido apresenta aspectos sociais que envolvem a vida literária, sendo a obra literária o verdadeiro motor da análise, e o social considerado um elemento estruturador da obra literária. Nesse sentido, para realizar a análise se conjuga os fatores sociais sem deixar de lado os valores estéticos da obra, tendo o social uma importância para a estrutura interna da obra, pois de acordo com Candido a arte é social por depender

[...] da ação de fatores do meio, que se exprimem na obra em graus diversos de sublimação; e produz sobre os indivíduos um efeito prático, modificando a sua conduta e concepção do mundo, ou reforçando neles o sentimento dos valores sociais. Isto decorre da própria natureza da obra e independe do grau de consciência que possam ter a respeito os artistas e os receptores de arte. (CANDIDO, 2010, p. 30)

No ensaio "De cortiço a cortiço", Antonio Candido interpreta a realidade das pessoas pobres, mais especificamente dos brasileiros livres daquele período, que trabalhavam e viviam amontoados nos cortiços, isto é, o dia-a-dia do homem que vive as margens da sociedade, que se encontram longe de alcançar o ideal de progresso. Interpreta as relações humanas, que desvendam as classes econômicas (CANDIDO, 1993), dessa forma, destacando a exploração do brasileiro, reduzido à condição de um carregador de carga, que trabalha para formar o capital de outros.

No referido ensaio apresenta a dialética entre a ordem e a desordem social, isso pode ser percebido de acordo com Antonio Candido, na obra O Cortiço de Aluísio Azevedo, quando depois do incêndio João Romão reconstruiu o cortiço de forma mais ordenada, passando assim da desordem para a ordem, e os moradores que não se adaptaram foram continuar no ritmo da desordem em outro cortiço que ficava próximo. Portanto, de acordo com Antonio Candido, a 
referida obra apresenta um modo de vida que pode definir o Brasil como um todo, ao apresentar vários tipos sociais (CANDIDO, 1993), mostrando assim o diálogo entre a literatura e a vida social.

Dessa forma, o referido crítico considera O cortiço de Aluísio Azevedo uma alegoria do Brasil, ao fazer um esboço das condições do país através do plano econômico de João Romão. Sendo que, Candido também observa a relação dialógica existente entre $O$ cortiço e L'Assomoir de Émile Zola, pelo motivo de ambas as obras apresentarem a vida do trabalhador pobre e morador de cortiço (CANDIDO, 1993).

Desse modo, podemos observar nos ensaios de Antonio Candido que os textos literários expõem os modos de vida e interesses de determinadas classes e grupos sociais, pois a literatura é uma representação da sociedade, ou seja, apresenta uma relação entre as estruturas vigentes. Em "De cortiço a cortiço" Antonio Candido procura mostrar que não importa o país, qualquer texto literário pode sofrer influência de outros. Dessa forma, podemos observar o olhar de sociólogo do referido crítico, pois

[...] vale lembrar que ele chegou à crítica literária e ao ensino de literatura depois de um curso de sociologia, disciplina que ensinou na Universidade de São Paulo entre 1942 e 1958, e que aliou e continua aliando a essa formação sociológica uma sólida e duradoura militância política de inspiração sociológica. (LAJOLO, 2003, p. 61)

Nesse sentido, podemos destacar que Antonio Candido apresenta uma visão de crítico e historiador literário, pois para ele, não há como analisar uma obra literária sem levar em conta o social, pois é através da literatura que podemos identificar o brasileiro, por isso a importância da literatura para entender a formação da identidade nacional.

Em "Dialética da malandragem" Antonio Candido aborda a questão do romance picaresco, malandro, documentário e representativo, destaca a representação de um personagem malandro, analisando o romance, Memórias de um sargento de milícias, produção literária de Manuel Antônio de Almeida, destacando a importância da referida obra para as letras nacionais, considerando-o novo, e não uma imitação de produções estrangeiras, observando a questão da ordem e da desordem social. A menção ao pícaro que Antonio Candido faz no ensaio "Dialética da malandragem" é justamente para excluir tal categoria da caracterização das Memórias de um sargento de milicias. Assim o crítico propõe uma forma específica, configurada a partir do contexto brasileiro: o romance malandro.

De acordo com Antonio Candido, a referida produção literária apresenta a relação entre a ordem e a desordem da sociedade brasileira do século XIX. Candido caracteriza a obra literária Memórias de um sargento de milícias do autor Manuel Antonio de Almeida, como de natureza popular e de memória, sendo "[...] constituído pela dialética da ordem e da desordem, que manifesta concretamente as relações humanas no plano do livro, do qual forma o sistema de referência." (CANDIDO, 1970, p. 71), mostrando que existem convenções sociais e que nem sempre as mesmas são levadas a cabo.

De acordo com Candido (1970), essa dialética pode ser encontrada na própria economia do livro, através da descrição e das relações, ou seja, em várias situações o autor Manuel Antonio de Almeida mostra o jogo dialético da ordem e da desordem. Conforme podemos observar por meio das concepções de Antonio Candido: 
[...] pai, mãe e filho são três nódulos de relações, positivas (pólo da ordem) e negativas (pólo da desordem), sendo que os dois primeiros constituem uma espécie de prefiguração do destino do terceiro. Leonardo Pataca, o pai, faz parte da ordem, como oficial de justiça; e apesar de ilegítima, sua relação com Maria da Hortaliça é habitual e quase normal segundo os costumes do tempo e da classe. [...] Leonardo Pai, representante da ordem, desce a sucessivos círculos da desordem e volta em seguida a uma posição relativamente sancionada, tangido pelas intervenções pachorrentas e brutais do major Vidigal -, personagem que existiu e deve ter sido fundamental numa cidade onde, segundo um observador da época, "há que evitar sair sozinho à noite e ser mais atento à sua segurança do que em qualquer outra parte, porque são freqüentes os roubos e crimes, apesar de a polícia ser lá tão encontradiça como areia do mar. (CANDIDO, 1970, p. 71)

Essa dialética é percebida por meio das relações humanas entre os personagens, formando assim dois mundos, os que pertencem ao mundo da ordem e os que fazem parte da desordem social. Antonio Candido procura mostrar que Memórias de um sargento de milícias é uma obra literária singular para a tradição literária nacional. Busca mostrar a sociedade através da referida obra literária, ou seja, ele não explica apenas a estrutura da obra, mas a fisionomia do Brasil que se formava na primeira metade do século XIX.

Nesse sentido, Antonio Candido aborda o diálogo entre literatura e sociedade, pois a figura do malando, que faz parte ao meio da desordem social, está presente tanto no meio social, como na ficção, estudando a literatura como sistema integrado de cultura. Desse modo, no dizer de Crespo (2003) os conceitos de Antonio Candido proporcionam um vasto campo de discussão, por apresentar essa relação entre literatura e a vida social.

Portanto, o crítico literário Antonio Candido iniciou uma nova forma de fazer análise literária, abordando o diálogo entre a nossa literatura e outras, destacando que as obras literárias não apresentam um diálogo apenas com o tempo, mas com outras obras, e que a produção cultural dialoga com a realidade do país. Dessa forma, o referido crítico mostra que a única literatura capaz do nos expressar é a brasileira.

\section{CONSIDERAÇÕES FINAIS}

A partir das considerações apresentadas nesse breve artigo, podemos confirmar que o pensamento crítico de Antonio Candido apresenta uma importância relevante para a crítica literária brasileira, ao abordar uma nova forma de fazer crítica, levando em consideração a relação dialógica entre a arte literária e a vida social. Por meio da leitura de algumas de suas obras podemos perceber o jogo dialético entre a literatura e a vida social, e como ele percebe a literatura como um sistema integrado de cultura.

Portanto, a obra de Antonio Candido é de suma importância para o cenário crítico brasileiro, ao fazer um intercâmbio entre a obra literária e a vida social. Dessa forma, Antonio Candido merece destaque, por fazer um estudo acerca da formação da literatura brasileira, por meio do desejo dos brasileiros de ter uma literatura nacional, e por meio de seu conceito materialista. Visto que, conforme o referido crítico literário, nós vivemos em um mundo interligado, dessa forma, por meio da literatura que nos exprime (literatura brasileira) podemos entender a literatura universal. 
É importante ressaltar também que através do conceito de sistema literário desenvolvido por Antonio Candido, podemos entender que o texto literário não pode ser considerado apenas pelos seus aspectos internos, mas conforme a legitimação que ele adquire dentro de um sistema literário. Percebemos como acontece a interação entre os autores, as obras e o público, ou seja, é por meio do sistema literário que percebemos as relações dialógicas existentes nas diversas obras literárias.

Podemos observar que os escritos de Antonio Candido não se esgotam, mas continuam nos debates teóricos contemporâneos. Desse modo, temos a capacidade de afirmar que Antonio Candido está entre os melhores críticos literários do Brasil. Outro ponto importante que merece destaque em sua crítica é o estudo que Candido faz acerca da relação dialógica entre a esfera da ordem e da desordem, que esse diálogo está presente nas esferas sociais e ficcionais, buscando o correlato social para explicar a forma.

Portanto, o social deve ser considerado como um elemento que desempenha um papel importante na construção do texto, ou seja, o social faz parte da estrutura interna do texto, pois de acordo com Candido, as obras literárias apresentam os modos de vida dos grupos sociais. Todo texto sofre influência, seja social ou de outros textos, dessa forma, para Antonio Candido a literatura só adquire um real sentido quando acontece a integração da mesma a um sistema cultural.

\section{REFERÊNCIAS BIBLIOGRÁFICAS}

BAKHTIN, Mikhail. Questões de literatura e estética: a teoria do romance. - São Paulo: HUCITEC, 1988.

BARBOSA, João Alexandre. Criação e Crítica Literária. In: Leituras desarquivadas. - Cotia, SP: Ateliê Editorial, 2007, p. 45-56.

. As escolhas de Antonio Candido. In: Leituras desarquivadas. - Cotia, SP: Ateliê Editorial, 2007.

CANDIDO, Antonio. Literatura e Sociedade. 11 ed. - Rio de Janeiro: Ouro sobre Azul, 2010.

CANDIDO, Antonio. De cortiço a cortiço. In: O discurso e a cidade. São Paulo: Duas cidades, 1993, p. 65-79

CANDIDO, Antonio. Dialética da Malandragem caracterização das Memórias de um sargento de milícias. In: Revista do Instituto de estudos brasileiros, no 8, São Paulo, USP, 1970, p. 67-89.

CANDIDO, Antonio. Formação da literatura brasileira: Momentos decisivos. 6. ed. Belo Horizonte, Editora Itatiaia Ltda, 2000.

CARDOSO, Sebastião Marques. Horizontes da crítica literária brasileira contemporânea: Roberto Schwarz e Luiz Costa Lima. In: VIOLA, Alan Flavio (Org.). Crítica literária contemporânea. - Rio de Janeiro: Civilização Brasileira, 2013. 
CRESPO, Regina. Antonio Candido e "nossa América" Literatura, história e política. In: SERNA, Jorge Ruedas de La (Org.). História e literatura: homenagem a Antonio Candido. Campina, SP: Editora da UNICAMP, Fundação Memorial da América Latina: São Paulo: Imprensa Oficial do estado, 2003, p. 93-114.

LAJOLO, Marisa. A leitura na Formação da literatura brasileira de Antonio Candido. In: SERNA, Jorge Ruedas de La (Org.). História e literatura: homenagem a Antonio Candido. Campina, SP: Editora da UNICAMP, Fundação Memorial da América Latina: São Paulo: Imprensa Oficial do estado, 2003, p. 51-75.

SCHWARZ, Roberto. Sobre a Formação da literatura brasileira. In: Sequiências brasileiras: ensaios. São Paulo: Companhia da Letras, 1999, p. 17-23.

SCHWARZ, Roberto. Adequação nacional e originalidade crítica. In: Seqüências brasileiras: ensaios. - São Paulo: Companhia da Letras, 1999, p. 24-45.

SCHWARZ, Roberto. Pressupostos, salvo engano, de "Dialética da malandragem". In: SCHWARZ, Roberto. Que horas são?: ensaios. - São Paulo: companhia das Letras, 1987, p. 129155.

SCHWARZ, Roberto. Nacional por subtração. In: SCHWARZ, Roberto. Que horas são?: ensaios. - São Paulo: companhia das Letras, 1987, p. 29-48. 